\title{
Diyabetik ayak hastalarının yaşam kalitesi ve etkileyen faktörler
}

\section{Quality of life of diabetic foot patients and affecting factors}

\author{
İsmail Toygar ${ }^{1}$ (D) \\ Sadık Hançerlioğlu ${ }^{1}$ \\ Ilgın Yıldırım Şimşir ${ }^{2}$ Şevki Çetinkalp ${ }^{2}$ (D) \\ ${ }^{1}$ Ege Üniversitesi Hemşirelik Fakültesi, İç Hastalıkları Hemşireliği Anabilim Dalı, İzmir, Türkiye \\ ${ }^{2}$ Ege Üniversitesi Tıp Fakültesi, İç Hastalıkları Anabilim Dalı, Endokrinoloji ve Metabolizma \\ Hastalıkları Bilim Dalı, İzmir, Türkiye
}

Öz

Amaç: Diyabetik ayak hastalarında yaşam kalitesi düzeylerinin ve etkileyen faktörlerin değerlendirilmesidir.

Gereç ve Yöntem: Çalışmanın verileri Ocak - Mart 2020 tarihleri arasında üniversite hastanesinin diyabetik ayak konseyine başvuran 171 hastadan toplanmıştır. Verilerin toplanmasında birey tanıtım formu ve Diyabetik Ayak Ölçeği - Kısa Formu kullanıımıştır. Bu ölçekte alt boyutlar ve ölçek toplam puanı 0-100 aralığında değerler almakta olup yüksek puan ortalaması yüksek yaşam kalitesini, düşük puan ortalaması düşük yaşam kalitesini göstermektedir. Araştırmanın verileri IBM SPSS 25.0 paket programı ile analiz edilmiştir.

Bulgular: Çalışmada yer alan hastaların \%67,3'ünün erkek, \%84,8'inin evli ve ortalama yaşı $61,57 \pm 10,03$ yıl olarak saptanmıştır. Kadınların $(p=0,009)$, insülin tedavisi alanların $(p=0,004)$, sigara kullanmayan $(p=0,027)$, alkol tüketimi olmayan $(p=0,030)$ ve diyabete eşlik eden kronik hastalığı olmayan bireylerin $(p=0,003)$ yaşam kalitesi puan ortalamalarının daha yüksek düzeyde olduğu saptanmıştır. Regresyon tahminlemesinde insülin tedavisi almanın $(\beta=-0,23, p=0,024)$ ve eşlik eden kronik bir hastalığı olmamasının $(\beta=-0,17, \quad p=0,037)$ yaşam kalitesini olumlu yönde etkilediği saptanmıştır.

Sonuç: Sonuç olarak diyabetik ayak hastalarında yaşam kalitesinin orta düzeyde olduğu cinsiyet, tedavi türü, sigara kullanımı, alkol kullanımı ve eşlik eden kronik hastalık varığı bakımından gruplar arasında farklıık olduğu gözlemlenmiştir. Diyabetik ayak hastalarında tedavi türü ve eşlik eden kronik hastalık varlığının yaşam kalitesi üzerine anlamlı etkisi olduğu saptanmıştır.

Anahtar Sözcükler: Diyabet, diyabetik ayak, yaşam kalitesi.

\begin{abstract}
Aim: To evaluate the quality of life of diabetic foot patients and affecting factors.

Materials and Methods: The data of the study were collected from 171 patients who applied to the diabetic foot council of a university hospital between January - March 2020. For the collection of the data, the individual identification form, and the Diabetic Foot Scale - Short Form were used. In this scale, the sub-dimensions' and scale total scores are range from 0 to 100, and the high mean score indicates a high quality of life, the low mean of score indicates a low quality of life. Research data were analyzed with IBM SPSS 25.0 software package.

Results: Of the patients, $67.3 \%$ were male, $84.8 \%$ were married, and the mean age was $61.57 \pm$ 10.03 years. The quality of life scores of women $(p=0.009)$, those receiving insulin therapy $(p=$ $0.004)$, non-smokers $(p=0.027)$, those who do not consume alcohol $(p=0.030)$, and individuals who do not have any concomitant chronic disease $(p=0.003)$ was found to be at a high level. In regression estimation, it was found that receiving insulin therapy $(\beta=-0.23, p=0.024)$ and not having any concomitant chronic disease $(\beta=-0.17, p=0.037)$ positively affected the quality of life.
\end{abstract}

\footnotetext{
Sorumlu yazar: İsmail Toygar

Ege Üniversitesi Hemşirelik Fakültesi, İç Hastalıkları

Hemşireliği Anabilim Dalı, İzmir, Türkiye

E-posta: ismail.toygar1@gmail.com

Başvuru Tarihi: 21.04.2020 Kabul Tarihi: 06.06.2020
} 
Conclusion: As a result, it was observed that the quality of life of diabetic foot patients was at a moderate level, and there was a difference between the groups in terms of gender, type of treatment, smoking, alcohol consumption and accompanying chronic disease. It was determined that the type of treatment and accompanying chronic disease have a significant effect on the quality of life in diabetic foot patients.

Keywords: Diabetes, diabetic foot, quality of life.

\section{Giriş}

Diabetes mellitus (DM), sistemik ve kronik komplikasyonlarla seyreden, görülme sıklığı giderek artmakta olan kronik, metabolik bir hastalıktır. Dünya genelinde 2019 yılı itibari ile 463 milyon bireyin diyabet olduğu tahmin edilmektedir. Bu sayı dünya nüfusunun $\% 9,3$ 'üne karşılık gelmektedir (1). Ülkemizde diyabet görülme sıklığı dünya ortalamasının üzerinde olup artış hızla devam etmektedir. Türkiye Diyabet, Hipertansiyon, Obezite ve Endokrinolojik Hastalıklar Prevelans Çalışması (TURDEP)'na göre 1998 yılında ülkemizde 20 yaş üzeri yetişkinlerde diyabet prevelansı \%7,2 olarak bildirilmektedir. TURDEP II çalışmasında ise Türk erişkin toplumunda diyabet sıklığının \%13,7'ye ulaştığı görülmüş olup, 12 yılda diyabet sıklığı $\% 90$ oranında artmıştır (2).

Diabetes mellitus etkin kontrol edilemediğinde akut ve kronik komplikasyonlar ile seyir etmektedir. Bu komplikasyonlar arasında bireyin yaşam kalitesini, beden imajını, rol performansını, bireyin, ailesinin ve toplumun sosyal ve ekonomik yapısını, daha da önemlisi yaşamını olumsuz etkileyen diyabetik ayak önemli bir konuma sahiptir $(2,3)$.

Diyabetik ayak etkin bir ayak bakımı yapılmadığı ve koruyucu önlemler alınmadığı takdirde sık gelişen bir komplikasyondur. 15 yıl ve üzeri diyabetik olan ve diyabetik metabolik kontrolü iyi olmayan hastalar, diyabetik ayak gelişimi için risk altındaki bireylerdir. Periferik nöropati gelişimi ve vasküler yetmezliklerin eklenebilmesi için bu süre yeterlidir. Diyabetin bir komplikasyonu olan nöropati, diyabete sıklıkla eşlik eden periferik arter hastalığı ve travmalar sonucunda diyabetik ayak gelişimi olasıdır. Diyabetik ayak, gelişiminden sonra etkin ve doğru tedavi edilmediğinde ampütasyon ile sonuçlanabilen ciddi bir komplikasyondur. Her diyabet hastasının yaşamı boyunca \%12-15 oranında diyabetik ayak ülseri gelişme riski vardır $(3,4)$.

Diyabetik ayakta kişinin yaşam kalitesinin değerlendirilmesi ve yaşam kalitesinin yükseltilmesine yönelik girişimler oldukça önemli bir yere sahiptir. Bu nedenle de yaşam kalitesi düzeyini ve etkileyen faktörleri değerlendirmek yaşam kalitesini yükseltmenin ilk basamağını oluşturmaktadır. Bu araştırma diyabetik ayak hastalarının yaşam kalitesi düzeylerini ve etkileyen faktörleri değerlendirmek amacı ile gerçekleştirilmiştir.

\section{Gereç ve Yöntem}

Araştırma tanımlayıcı nitelikte olup, Ocak - Mart 2020 tarihleri arasında üniversite hastanesinin diyabetik ayak konseyine başvuran hastalar üzerinde gerçekleştirilmiştir.

\section{Katılımcılar}

Araştırmaya 18 yaş ve üzerinde, en az bir aydır diyabetik ayak tanısı bulunan, Türkçe iletişim kurabilen, düşünsel yetisini bozabilecek bir rahatsızlığı bulunmayan ve araştırmada yer almayı kabul eden toplam 171 birey dahil edilmiştir.

\section{Verilerin Toplanması}

Veriler bir araştırmacı tarafından ayrı bir odada yüzyüze görüşme tekniği ile toplanmıştır. Araştırmacı soruları sorup, hastaların verdikleri cevaplar doğrultusunda formlara işaretlemeleri gerçekleştirmiştir. Verilerin toplanmasında hasta tanıtım formu ve Diyabetik Ayak Ölçeği - Kısa Form'u kullanılmıştır.

Birey Tanııı Formu: Hastanın yaşı, cinsiyeti, medeni durumu ve hastalık süresi ve tedavi şekli gibi toplamda 20 adet sorudan oluşmaktadır.

Diyabetik Ayak Ölçeği - Kısa Formu (DAÖKF): Bann ve arkadaşları tarafından 2003 yılında geliştirilmiştir. Ölçek 2002 yılında geliştirilen 64 maddelik Diyabetik Ayak Ülser Ölçeği'nin kısaltılmış versiyonudur. Toplamda 29 maddeden oluşmaktadır. Ölçeğin alt boyut hesaplamasında alt boyutlara göre yüzdeler üzerinden skorlar elde edilmektedir. Daha yüksek skorlar yaşam kalitesinin daha yüksek olduğunu göstermektedir (5). Ölçeğin Türkçe'ye geçerlik güvenirliği Toygar ve Arkadaşları (2019) tarafından gerçekleştirilmiştir. Ölçek Türk toplumunda diyabetik ayak hastalarının yaşam kalitesini 
ölçede geçerli ve güvenilir olarak bildirilmiştir. Chronbach Alfa değeri 0,81 ile 0,94 arasında bildirilmiştir (6).

\section{Verilerin Analizi}

Verilerin analizinde SPSS 25.0 paket programı kullanılmıştır. Çalışmanın tanımlayıcı verilerinin frekans ve ortalama ile değerlendirilmiştir. Bu veriler sayı, yüzde ve ortalama olarak sunulmuştur. Grup sayısı düşük olan kategorilerde (Eğitim Düzeyi ve Wagner
Sınıflandırması) analizler için gruplar birleştirilmiştir. Grup içi ve gruplar arası karşılaştırmalar için öncelikli olarak verilerin normal dağılımı Shapiro-Wilk ve Kolmagorow Smirnow testleri ile değerlendirilmiştir. Verilerin normal dağıldığı durumlarda parametrik, normal dağılmadığı durumlarda nonparametrik testler kullanılmıştır. Çoklu gruplarda grup içi ileri karşılaştırmalar için Post hoc Dunn Testi kullanılmıştır. İstatistiksel anlamlılık düzeyi olarak $p<0,05$ değeri kabul edilmiştir.

Tablo-1. Katılımcıların sosyodemografik ve hastalık ile ilişkili bulgularının dağılımı.

\begin{tabular}{|c|c|c|c|}
\hline & & $\mathbf{n}$ & $\%$ \\
\hline \multirow{2}{*}{ Cinsiyet } & Kadın & 56 & 32,7 \\
\hline & Erkek & 115 & 67,3 \\
\hline \multirow{3}{*}{ Medeni Durum } & Evli & 145 & 84,8 \\
\hline & Bekar & 26 & 15,2 \\
\hline & İlköğretim & 141 & 82,5 \\
\hline \multirow[t]{3}{*}{ Eğitim Düzeyi } & Lise & 21 & 12,3 \\
\hline & Üniversite & 9 & 5,2 \\
\hline & Gelir giderden az & 67 & 39,2 \\
\hline \multirow[t]{3}{*}{ Gelir Düzeyi } & Gelir gidere denk & 96 & 56,1 \\
\hline & Gelir giderden fazla & 8 & 4,7 \\
\hline & İ & 41 & 24,0 \\
\hline \multirow[t]{2}{*}{ Yaşadığı Yer } & İlçe & 111 & 69,9 \\
\hline & Köy & 19 & 11,1 \\
\hline \multirow{2}{*}{ Sigara Kullanımı } & Evet & 86 & 50,3 \\
\hline & Hayır & 85 & 49,7 \\
\hline \multirow{2}{*}{ Alkol Tüketimi } & Evet & 29 & 17,0 \\
\hline & Hayır & 142 & 83,0 \\
\hline \multirow{2}{*}{ Tedavi Türü } & İnsülin & 142 & 83,0 \\
\hline & Oral Antidiyabetik & 29 & 17,0 \\
\hline \multirow{5}{*}{ Wagner Sınıflandırması } & Wagner 1 & 19 & 11,1 \\
\hline & Wagner 2 & 50 & 29,2 \\
\hline & Wagner 3 & 70 & 40,9 \\
\hline & Wagner 4 & 23 & 13,5 \\
\hline & Wagner 5 & 9 & 5,3 \\
\hline \multirow{2}{*}{$\begin{array}{l}\text { Diyabete eşlik eden başka } \\
\text { kronik hastalık }\end{array}$} & Var & 115 & 67,3 \\
\hline & Yok & 56 & 32,7 \\
\hline \multirow{3}{*}{$\begin{array}{l}\text { Düzenli hekim } \\
\text { kontrolü/takibi }\end{array}$} & Var & 130 & 76,0 \\
\hline & Yok & 41 & 24,0 \\
\hline & & \multicolumn{2}{|c|}{ Ortalama $\pm S S$} \\
\hline \multicolumn{2}{|l|}{ Yaş } & \multicolumn{2}{|c|}{$61,57 \pm 10,03$} \\
\hline \multicolumn{2}{|l|}{ Diyabet hastalık süresi (yıl) } & \multicolumn{2}{|c|}{$15,22 \pm 12,53$} \\
\hline
\end{tabular}




\section{Etik}

Araştırmanın yürütülebilmesi için Ege Üniversitesi Tıbbi Araştırmalar Etik Kurulu'ndan (Protokol No:20-4.1T/22), araştırmanın yürütüleceği Ege Üniversitesi Tıp Fakültesi Hastanesi Endokrinoloji Bilim Dalı'ndan ve katılımcılardan yazılı izin alınmıştır. Araştırmanın yürütülmesinde Helsinki Bildirgesi'nin tüm maddeleri göz önünde bulundurulmuş, tüm katıımcılara aydınlatılmış onam açıklanmış ve imzalatılmıştır.

\section{Bulgular}

Katılımcıların \%67,3'ü erkek, \%84,8'i evli, \%82,5'i ilköğretim mezunu yaş ortalaması $61,57 \pm 10,03$ idi. Katılımcıların \%56,1'i gelir düzeyinin giderine eşit olduğunu ve \%69,9'u ilçede yaşadığını bildirmiştir. Hastaların \%50,3'ü sigara, \%17'si ise alkol kullandıklarını bildirmişlerdir. Hastaların \%83'ü diyabetin yönetiminde insülin tedavisi alırken, diyabetik ayak ülserlerinin \%40,9'u Wagner 3 sınıflandırmasında yer almaktadır. Hastaların ortalama $15,22 \pm 12,53$ yıldır bilinen diyabet tanısı bulunmakta ve \%67,3'ünde diyabete en az bir diğer kronik hastalık eşlik etmektedir. Hastaların \%76'sı düzenli olarak doktor takibinde olduklarını bildirmişlerdir (Tablo-1).

Bireylerin yaşam kalitesi puan ortalamaları ölçek toplam puanı için $62,26 \pm 18,31$ iken alt boyutlar için sırası ile; lezyon $65,36 \pm 25,47$, fiziksel sağılı $63,67 \pm 22,6$, bağımlılık/günlük yaşam aktiviteleri $76,9 \pm 27,14$, olumsuz duygular $60,23 \pm 23,83$, ülser hakkındaki kaygılar $60,47 \pm 28,16$ ve ülser bakımından bezmişlik $62,40 \pm 25,12$ olarak saptanmıştır. Kadınların lezyon $(p=0,005)$, fiziksel sağlık $(p=0,019)$, bağımlılık/günlük yaşam aktiviteleri $(p=0,001)$, ülser bakımından bezmişlik $(p=0,029)$ ve ölçek toplam puanında $(p=0,009)$ erkeklerden istatistiksel anlamlı düzeyde daha yüksek skorlar elde ettiği saptanmıştır. Lise ve üniversite mezunu bireylerin ilköğretim mezunu bireylere oranla olumsuz duygular alt boyut puan ortalamasının $(p=0,011)$ istatistiksel anlamlı düzeyde daha yüksek olduğu saptanmıştır. Sigara kullanan bireylerin bağımlılık/günlük yaşam aktiviteleri $(p=0,007)$, ülser hakkındaki kaygılar $(0,009)$, ülser bakımından bezmişlik $(p=0,017)$ alt boyutları ve ölçek toplam puanında $(p=0,027)$ sigara kullanmayan bireylerden istatistiksel anlamlı düzeyde daha düşük puanlar elde ettiği saptanmıştır. Alkol tüketen bireylerde ise bağımlılık/günlük yaşam aktivileteri alt boyutu $(p=0,002)$ ve ölçek toplam puanının $(p=0,030)$ istatistiksel anlamlı düzeyde daha düşük olduğu saptanmıştır. İnsülin tedavisi alan bireylerin lezyon ( $p<0,001)$, fiziksel sağlık $(p=0,007)$, ülser hakkındaki kaygılar $(p=0,009)$, ülser bakımından bezmişlik $(p=0,017)$ altboyutları ve ölçek toplam puanı $(p=0,027)$ yönünden oral antidiyabetik tedavisi alan bireylerden istatistiksel anlamlı düzeyde daha yüksek puanlar elde ettiği gözlemlenmiştir. Diyabete eşlik eden en az bir kronik hastalığı bulunan bireylerin lezyon $(p<0,001)$, olumsuz duygular $(p=0,017)$, ülser hakkındaki kaygılar $(p=0,002)$ alt boyutları ve toplam puan ortalaması $(p=0,003)$ yönünden diyabete eşlik eden kronik hastalığı olmayan bireylere oranla istatistiksel anlamlı düzeyde daha düşük olduğu saptanmıştır (Tablo-2).

Ölçek toplam puanın bakımından gruplar arasında farklılık saptanan değişkenlerin ölçek toplam puanı üzerine etkisinin tahminlenmesinde regresyon analizi kullanımıştır. $\mathrm{Bu}$ analiz sonucuna göre hastalara uygulanan tedavi türünün $(p=0,024)$ ve diyabete eşlik eden bir başka kronik hastalık varlığının $(p=0,037)$ yaşam kalitesini istatistiksel anlamlı düzeyde etkilediği saptanmıştır. İnsülin tedavisinin ve diyabete eşlik eden bir kronik hastalığın bulunmamasının yaşam kalitesini arttırdığı saptanmıştır (Tablo-3). 


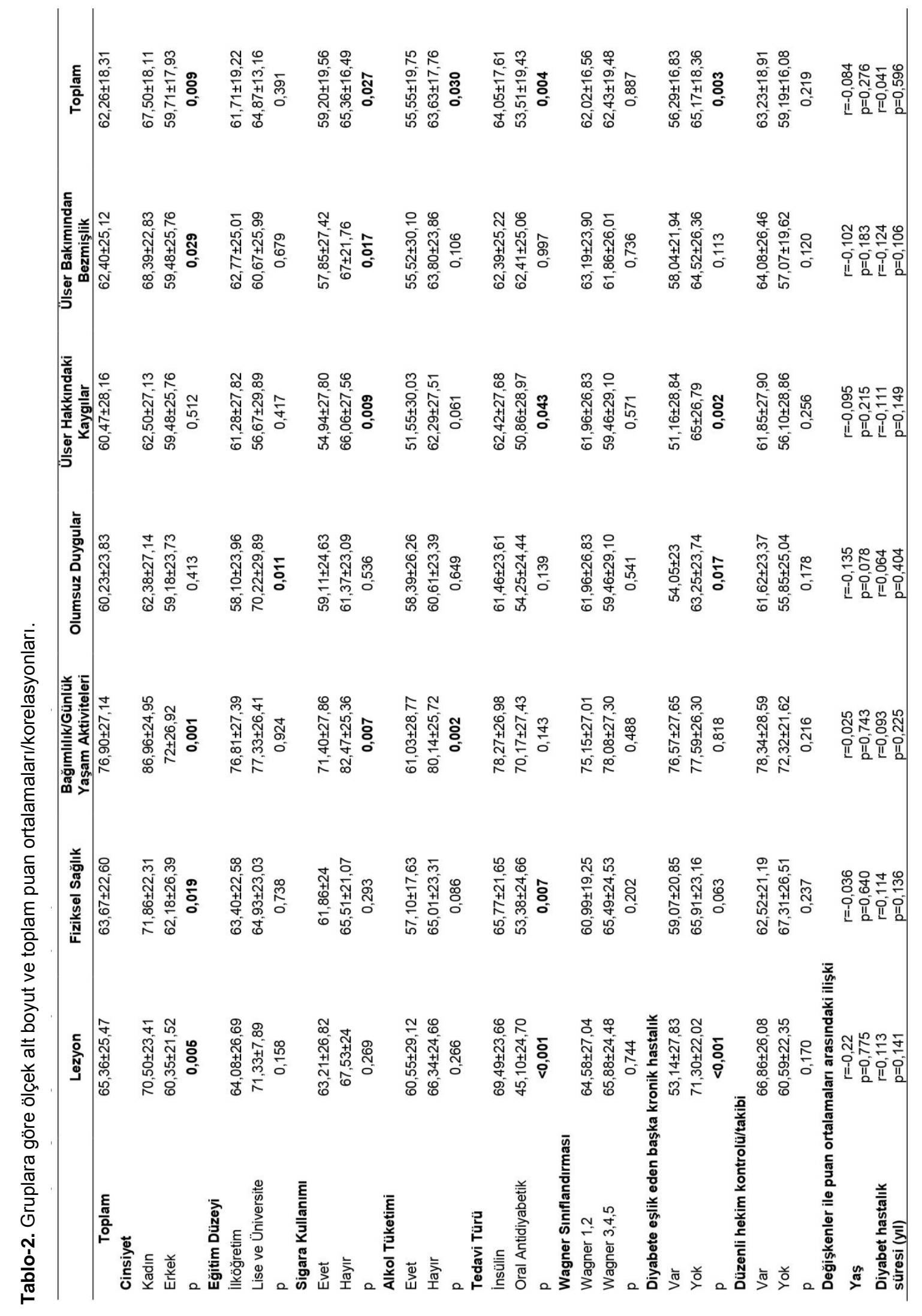


Tablo-3. Değişkenlerin yaşam kalitesi üzerine etkisine ilişkin regresyon tahminlemesi.

\begin{tabular}{lllll}
\hline & \multicolumn{1}{c}{$\begin{array}{c}\text { Standardize Katsayı } \\
\mathbf{B}(\% 95 \text { Cl) }\end{array}$} & $\boldsymbol{\beta}$ & $\mathbf{t}$ & $\mathbf{p}$ \\
\hline Sabit & $68,26(48.20: 88.32)$ & - & 6,72 & $<0,001$ \\
Cinsiyet & $-4,90(-10.73: 0.93)$ & $-0,13$ & $-1,66$ & 0,099 \\
Tedavi türü & $-6,15(-14.01: 1.70)$ & $-0,23$ & $-1,55$ & $\mathbf{0 , 0 2 4}$ \\
Sigara kullanımı & $3,94(-1.54: 1.70)$ & 0,11 & 1,42 & 0,157 \\
Alkol tüketimi & $6,67(-0.52: 13.86)$ & 0,14 & 1,83 & 0,069 \\
\hline
\end{tabular}

\section{Tartışma}

Diyabetik ayak bireylerin yaşantısını bir çok alanda olumsuz etkileyen bir komplikasyondur ve dolayısı ile bireyin yaşam kalitesini de etkilemektedir. Diyabetik ayak tanılı bireylerde yaşam kalitesinin yükseltilmesi bakımın temel amaçları arasında yer almaktadır. Diyabetik ayak tanılı bireyin yaşam kalitesinin yükseltilmesi için yaşam kalitesini etkileyen faktörlerin tanımlanması gerekmektedir $(3,4)$. Bu araştırma ülkemizde diyabetik ayak tanılı bireylerde yaşam kalitesi düzeyini ve etkileyen faktörleri tanımlamak amacı ile gerçekleştirilmiştir.

Çalışmamızda kadınların yaşam kalitesi düzeyinin erkeklerinkinden daha yüksek olduğu saptanmıştır. Prasannakumar ve ark. (7) tip 2 diyabet hastalarında gerçekleştirdikleri çalışmada kadın hastaların yaşam kalitelerinin erkek hastalardan daha yüksek olduğunu bildirmiştir. Levterova ve ark. (8) tip 2 diyabet hastalarında gerçekleştirdiği çalışmada ise erkek hastaların yaşam kalitesinin kadınlardan daha yüksek düzeyde olduğu bildirilmiştir. Cinsiyet ve yaşam kalitesi arasındaki ilişkinin toplumun yapı ve kültürüne göre değişiklik gösterdiği gözlemlenmektedir. Diyabetik ayak gelişen bireylerde yara iyileşmesinin sağlıklı bir şekilde gerçekleşmesi ve ağrının azaltılması için yara gelişen ayağa binen yükün azaltılması gerekmektedir (3, 4). Ülkemizde ise erkeklerin fiziksel güç gerektiren işlerde çalışması, günlük ev içi yaşamlarında da fiziksel güç gerektiren roller üstlenmesi nedeni ile diyabetik ayaktan daha fazla etkilendikleri düşünülmektedir (9). Lezyon, fiziksel sağlık, bağımlılık/günlük yaşam aktiviteleri ve ülser bakımından bezmişlik gibi diyabetik ayağın fiziksel yakınmaları ile ilişsili alt boyutlarında gruplar arasında farklılık görülürken, olumsuz duygular ve ülser hakkındaki kaygılar gibi psikolojik yakınmaları içeren alt boyutlarda gruplar arasında farklılık gözlemlenmemesi bu savı desteklemektedir.

Çalışmamızda lise ve üniversite mezunu bireylerin olumsuz duygular alt boyutunda ilköğretim mezunu bireylerden daha yüksek puanlar aldığı saptanmıştır. Nikolaev (10) daha yüksek eğitim düzeyindeki bireylerin daha yüksek subjektif iyilik halinde olduğunu bildirmektedir. Eğitim düzeyinin genel subjektif iyilik hali üzerine olan etkisinin bu alt boyutta elde edilen sonuç ile ilişkili olduğu düşünülmektedir.

Sigara kullanan bireylerde ise bağımlılık/günlük yaşam aktiviteleri, ülser hakkındaki kaygılar, ülser bakımından bezmişlik alt boyutu ve ölçek toplam puanında istatistiksel olarak daha düşük skorlar gözlemlenmiştir. Hastalık Kontrol ve Önleme Merkezi (11) sigara kullanan bireylerin hiç sigara kullanmamış bireylere oranla yaşam kalitelerinin daha düşük düzeyde olduğunu bildirmektedir. Rezaei ve ark. (12) İran'da yaptıkları bir diğer çalışmada da sigara kullanan bireylerin yaşam kalitelerinin daha düşük düzeyde olduğu bildirilmektedir. Çalışmamız bu sonucu ile literatürle uyum göstermektedir.

Çalışmamızda alkol tüketiminin bağımlılık/günlük yaşam aktiviteleri alt boyutu ve ölçek toplam puanı üzerine negatif yönlü etkisi olduğu gözlemlenmiştir. Literatürde alkol kullanımının yaşam kalitesi üzerine etkisinin değerlendirildiği çalışmalarda alkol kullanım sıklığı ve miktarına göre farklı sonuçlar bildirilmektedir. Alkol tüketim düzeyine göre yaşam kalitesinin arttığı ya da azaldığı çalışmalar bulunmaktadır (13-15). Çalışmamızda bireylerin alkol kullanım sıklığı ya da miktarına dair bir değerlendirme gerçekleştirilmemiştir. Bu noktada diyabetik ayak hastalarında alkol kullanımı ile yaşam kalitesi arasındaki ilişkinin değerlendirilmesinde bu 
faktörlerinde göz önünde bulundurulduğu ileri çalışmalar önerilmektedir.

İnsülin tedavisi alan bireylerde lezyon, fiziksel sağlık, ülser hakkındaki kaygılar ve ölçek toplam puan ortalamalarının daha yüksek olduğu saptanmıştır. Pouwer ve Hermanns'ın (16) diyabet hastalarında insülin tedavisinin yaşam kalitesi üzerine etkisini değerlendiren çalışmaları inceledikleri bir derlemede insülin tedavisinin yaşam kalitesi üzerine istatistiksel anlamlı düzeyde etkisinin olmadığını bildirmişlerdir. Fakat diyabetik ayakta insülinin farklı etkileri öngörülmektedir. Emanuelli ve ark. (17) insülinin immün hücreler, damar yapısı, epidermal ve dermal hücrelerin fornksiyonunu düzgün bir şekilde çalışmasını sağladığını dolayısı ile yara iyileşmesini hızlandırdığını bildirmiş̧lerdir. Ayrıca insülinin fibroblast fonksiyonu üzerine olumlu etkisi ile proliferasyonu artırdığı ve kollajen üretimini sağladığı da bildirilmektedir (17). İnsülin tedavisi alan bireylerde yaşam kalitesinin daha yüksek olmasının insülin sistemik etkileri ile değil, lezyon ve yara iyileşmesi ile ilişkili olduğu düşünülmektedir.

Çalışmamızda yaranın Wagner sınıflaması ile alt boyut ve ölçek toplam puan ortalamaları arasında istatistiksel anlamlı farklılık saptanmamıştır. Literatürde yaranın Wagner sınıflandırmasının artmasının yaşam kalitesini olumsuz yönde etkilediği bildirilmektedir (18). Çalışmamızda bu bulgunun literatürden farklı saptanmasının Wagner sınıflandırmasında farklı kategorilerde yer alan verilerin azlığının istatistiksel anlamlılığı etkileyebileceği düşüncesi ile kategorilerin birleştirilmesi ile ilişkili olabileceği düşünülmektedir. Bu konuda ülkemizde Wagner sınıflandırmasının yaşam kalitesi üzerine etkisinin değerlendirmesinde katmanlı örneklem ile gruplarda eşit sayıda veri olan ileri çalışmalar önerilmektedir.

Diyabete eşlik eden kronik hastalık varlığı durumunda lezyon, olumsuz duygular, ülser hakkındaki kaygılar alt boyutları ve ölçek toplam puanının azaldığı görülmüştür. Javanbakht ve ark. (19) gerçekleştirdikleri çalışmada diyabete eşlik eden komorbiditelerin yaşam kalitesini olumsuz yönde etkilediğini bildirmişlerdir (19).
Spasic ve ark. (20) yaptıkları çalışmada komorbidite ile düşük yaşam kalitesi arasında ilişki bildirmişlerdir. Çalışmamı bu yönü ile literatürle uyum göstermektedir.

Gruplar arasındaki ilişki değerlendirildiğinde cinsiyet, sigara kullanımı, alkol tüketimi, tedavi türü ve eşlik eden kronik hastalık bulunması konusunda gruplar arasında istatistiksel anlamlı farklılık saptanmasına karşın regresyon tahminlemesinde bu değişkenlerden yalnızca tedavi türü ve eşlik eden kronik hastalığın bulunmasının yaşam kalitesi üzerine anlamlı etkisi saptanmıştır.

\section{Sınırlılıklar}

Çalışmanın çeşitli sınırıııkları bulunmaktadır. Bunlar; çalışma tek merkezde yürütülmesi, değişkenlerden alkol tüketim düzeyinin değerlendirilmemesi ve Wagner sınıflandırmasında gruplar arası karşılaştırmalar için katmanlı örneklem kullanılmamasıdır.

\section{Sonuç}

Sonuç olarak kadınların, sigara kullanmayan, alkol tüketimi olmayan, insülin tedavisi alan ve eşlik eden bir kronik hastalığı bulunmayan bireylerin yaşam kalitesinin daha yüksek olduğu saptanmıştır. Bu değişkenlerin yaşam kalitesi üzerine etkisinin tahminlenmesinde ise tedavi türü ve eşlik eden bir kronik hastalığın olmasının diyabetik ayakta yaşam kalitesi üzerine istatistiksel anlamlı etkisi olduğu saptanmıştır. Diyabetik ayak tanılı bireylerin yaşam kalitelerinin değerlendirilmesinde ve yükseltilmesine yönelik planlamaların yapılmasında bu değişkenlerin göz önünde bulundurulmasını önermekteyiz. Konu ile ilgili ileri araştırmalar önerilmektedir.

\section{Teşekkür}

Araştırmaya gösterdikleri katılım için hastalara ve araştırmaların istatistiksel analizinin gerçekleştirilmesinde gösterdiği katkılar için Su Özgür'e teşekkürlerimizi sunarız.

\section{Çıkar çatışması}

Yazarlar araştırmada herhangi bir çıkar çatışması bulunmadığını bildirmektedir. 


\section{Kaynaklar}

1. Saeedi P, Petersohn I, Salpea, P, et al. Global and regional diabetes prevalence estimates for 2019 and projections for 2030 and 2045: Results from the International Diabetes Federation Diabetes Atlas. Diabetes Res Clin Pract 2019; 157: 107843.

2. Satman I, Grubu TIÇ. TURDEP-II Sonuçları. Türk Endokronoloji ve Metabolizma Derneği [Updated: 2011 Cited: 23.03.2020]. Avaible from: http://www.turkendokrin.org/files/file/TURDEP_ II_2011.pdf Son Erişim Tarihi: 23.03.2020.

3. Al-Rubeaan K, Al Derwish M, Ouizi S, et al. Diabetic foot complications and their risk factors from a large retrospective cohort study. PLoS One 2015; 10 (5): e0124446.

4. Nather A, Bee CS, Huak CY, et al. Epidemiology of diabetic foot problems and predictive factors for limb loss. J Diabetes Complications 2008; 22 (2): 77-82.

5. Bann CM, Fehnel SE, Gagnon DD. Development and validation of the Diabetic Foot Ulcer Scale-short form (DFS-SF). Pharmacoeconomics 2013; 21 (17): 1277-90.

6. Toygar I, Hançerlioğlu S, Gül S, Utku T, Yıldırım Şimşir I, Çetinkalp Ş. Turkish Adaptation of Diabetic Foot Ulcer Scale - Short Form. International Journal of Lower Extremity Wounds The International Journal of Lower Extremity Wounds. 2020; 19 (3): 269-274.

7. PrasannaKumar HR, Mahesh MG, Menon VB, Srinath KM, Shashidhara KC, Ashok P. Patient Self-reported quality of life assessment in Type 2 diabetes mellitus: A pilot study. Niger J Clin Pract 2018; 21: 343-9.

8. Levterova B, Levterov G, Dragova E. Quality of life in patients with type 2 diabetes mellitus in Bulgaria: a cross-sectional study. European Journal of Preventive Medicine 2016; 4 (1): 7-12.

9. Vatandaş C. Toplumsal Cinsiyet ve Cinsiyet Rollerinin Algılanışı. Sosyoloji Konferansları, 2007; (35): 29-56.

10. Nikolaev B. Does higher education increase hedonic and eudaimonic happiness?. J Happiness Stud 2018; 19 (2): 483-504.

11. Zack MM, Centers for Disease Control and Prevention (CDC). Health-related quality of life-United States, 2006 and 2010. MMWR Surveill Summ 2013; 62 (Suppl 3): 105-11.

12. Rezaei S, Matin BK, Karyani AK, et al. Impact of smoking on health-related quality of life: a general population survey in West Iran. Asian Pac J Cancer Prev 2017; 18 (11): 3179-85.

13. Beccaria $F$, Rolando $S$, Ascani $P$. Alcohol consumption and quality of life among young adults: a comparison among three European countries. Substance use misuse 2012; 47 (11): 1214-23.

14. Kaplan MS, Huguet N, Feeny D, et al. Alcohol use patterns and trajectories of health-related quality of life in middle-aged and older adults: a 14-year population-based study. J Stud Alcohol Drugs 2012; 73 (4): 581-90.

15. Schrieks IC, Wei MY, Rimm EB, et al. Bidirectional associations between alcohol consumption and healthrelated quality of life amongst young and middle-aged women. J Intern Med 2016; 279 (4): 376-87.

16. Pouwer F, Hermanns N. Insulin therapy and quality of life. A review. Diabetes Metab Res Rev 2009; 25 (Suppl 1): 4-10.

17. Emanuelli T, Burgeiro A, Carvalho E. Effects of insulin on the skin: possible healing benefits for diabetic foot ulcers. Arch Dermatol Res 2016; 308 (10): 677-94.

18. Yekta Z, Pourali R, Ghasemi-rad M. Comparison of demographic and clinical characteristics influencing health-related quality of life in patients with diabetic foot ulcers and those without foot ulcers. Diabetes Metab Syndr Obes 2011; 4: 393-9.

19. Javanbakht M, Abolhasani F, Mashayekhi A, Baradaran HR. Health related quality of life in patients with type 2 diabetes mellitus in Iran: a national survey. PloS one 2012; 7 (8): e4452

20. Spasić A, Radovanović RV, Đorđević AC, Stefanović N, Cvetković T. Quality of life in type 2 diabetic patients. Acta Fac Med 2014; 31 (3): 193-200. 